\title{
Distinguishing sex from sexual violation: Consent, negotiation and freedom to negotiate
}

\author{
Tanya Palmer
}

\section{Citation}

Tanya Palmer, 'Distinguishing Sex from Sexual Violation: Consent, Negotiation and Freedom to Negotiate' in Alan Reed, Michael Bohlander, Nicola Wake and Emma Smith (eds.) Consent: Domestic and Comparative Perspectives (Routledge, 2017).

\begin{abstract}
$* * *$
\section{Abstract}

This chapter argues that consent is not an appropriate or effective way to distinguish legitimate sexual activity from sexual violation. Consent is enmeshed with a particular notion of the Kantian liberal subject and as such is inapt to respond to the bodily, affective and relational aspects of subjectivity in general and sexual subjectivity specifically. To champion consent as the standard for legitimate sexual activity implies that sexual relations are inherently asymmetric, obscures the context within which agreements to engage in sexual activity are made, and overlooks the fluid and variable nature of sexual activity itself that renders it illsuited to a consent framework.
\end{abstract}

The Chapter considers alternative models of sex and sexual violation based on notions of communication and negotiation. Drawing on these models alongside theoretical argument and original empirical data, a new framework of 'freedom to negotiate' is proposed. The standard of 'freedom to negotiate' does not prescribe the form or content that any negotiation must take. It emphasizes instead the context in which sexual activity takes place, requiring that, at a minimum, all parties to sexual activity should have the space to negotiate both the fact and nature of their participation throughout the duration of that activity.

$* * *$

\section{Introduction}

Consent has become the dominant paradigm in legal and lay discourses for distinguishing sex from sexual violation. However, consent based models of sexual offending are flawed in a number of respects. The first two parts of this chapter explore respectively the reasons why consent has been embraced as a framework for evaluating sexual encounters and the problems with this framework, concluding that consent is not an appropriate standard by which to distinguish sex from sexual violation. The third part of the chapter introduces negotiation as a potential alternative framework, focusing on two specific law reform proposals put forward by Lois Pineau and Michelle Anderson. This work offers valuable insights for rethinking the sexual offences so as to better reflect the reality of sexual encounters, but also reproduces some of the problematic aspects of consent frameworks. The final part of the chapter draws on these 
models alongside original empirical data to develop a concept of 'freedom to negotiate'. This is proposed as a viable basis around which to reframe sexual offences law.

\section{Consent as the dominant paradigm in sexual offences law}

Consent is the primary dividing line between sex and sexual violation in English and Welsh law. It was recognised as a crucial element of the crime of rape as far back as the mid nineteenth century, ${ }^{1}$ and has become increasingly central to sex offences law, having been included within the first statutory definition of rape in $1976^{2}$ and enshrined as the pivotal element of rape and sexual assault in the Sexual Offences Act 2003. ${ }^{3}$ More recently, the European Court of Human Rights has affirmed that all non-consensual sex, not just that involving physical violence, is rape. ${ }^{4}$ Numerous legal scholars have endorsed the definition of rape and sexual assault as nonconsensual sexual activity and have explored in detail the specific form consent has taken and should take in sexual offences law. ${ }^{5}$

The legal reforms which have placed consent at the centre of sexual offences law have been widely embraced in large part because they emerged as a progressive shift from previous constructions of rape and sexual assault. Earlier definitions of rape emphasized physical force on the part of the perpetrator and resistance on the part of the victim, neither of which are required under a consent-based definition. ${ }^{6}$ The latter therefore protects a greater number of people from having sexual activity imposed upon them against their will and has thus been broadly — though not universally — welcomed by feminist and women's movements. ${ }^{7}$ At the same time, situating consent as the marker of legitimate sexual activity provides a basis for resisting the criminalization of sexual acts that fall foul of conservative Christian sexual morality, eg anal sex and/or sexual activity between two or more men. Hence consent has also been championed by the gay rights movement and other sexual minorities.

Despite academic and popular support for the consent paradigm, sexual offending remains a highly problematic area of criminal law and criminal justice. Rates of victimization

\footnotetext{
${ }^{1}$ R v Camplin (1845) 1 Cox 220. See also Bradley (1910) 4 Cr App R 225, in which it was held that the burden lies with the prosecution to prove that the victim did not consent.

${ }^{2}$ Sexual Offences (Amendment) Act 1976 s 1(1).

${ }^{3}$ Sexual Offences Act 2003 ss1-4.

${ }^{4}$ MC v Bulgaria (2005) 40 EHRR 20; Joanne Conaghan, 'Extending the Reach of Human Rights to Encompass Victims of Rape: M.C. v Bulgaria' (2005) 13 Feminist Legal Studies 145.

${ }^{5}$ See for example, Douglas Husak and George Thomas, 'Date Rape, Social Convention and Reasonable Mistakes' (1992) 11 Law and Philosophy 95; Jennifer Temkin and Andrew Ashworth, 'The Sexual Offences Act 2003: Rape, Sexual Assault and the Problems of Consent' (2004) Criminal Law Review 328; Sharon Cowan, 'Choosing Freely: Theoretically Reframing the Concept of Consent' in Rosemary Hunter and Sharon Cowan (eds), Choice and Consent: Feminist Engagements with Law and Subjectivity (Routledge 2007); Catherine Elliott and Claire de Than, 'The Case for a Rational reconstruction of Consent in Criminal Law' (2007) 70 The Modern Law Review 225; Vanessa Munro, 'Constructing Consent: Legislating Freedom and Legitimating Constraint in the Expression of Sexual Autonomy' (2008) 41 Akron Law Review 923; Michelle Dempsey, 'Victimless Consent and the Volenti Maxim: How Consent Works' (2013) 7 Criminal Law and Philosophy 11.

${ }^{6}$ Vanessa Munro, 'From Consent to Coercion: Evaluating International and Domestic Frameworks for the Criminalization of Rape' in Clare McGlynn and Vanessa Munro (eds), Rethinking Rape Law: International and Comparative Perspectives (Routledge 2010).

${ }^{7}$ ibid.
} 
are consistently high, whilst reporting and conviction rates are low. ${ }^{8}$ In addition, reforms to the substantive law have not prevented factors other than consent - such as the infliction of physical injuries, the status of the relationship between the complainant and the accused, and the behaviour of the complainant after an alleged rape - from influencing the judgements of actors at every stage of the criminal process. ${ }^{9}$ These difficulties are often interpreted as resulting from the relevant actors failing to properly apply consent to the facts; the status of consent itself as the dividing line between sex and sexual violation frequently goes unchallenged. ${ }^{10}$ This perception that consent is not being properly understood underpinned the introduction of a statutory definition of consent in the Sexual Offences Act 2003, ${ }^{11}$ as well as calls for consent to be included in sex education programmes at both school and university level. ${ }^{12}$ It is, however, far from clear that all those advocating a consent-based definition of sex and sexual violation are using the term 'consent' in the same way.

Consent is an ambiguous concept. There is a lack of consensus as to whether consent consists of a mental state or some external performance; ${ }^{13}$ and even within these broad categories consent could consist of a range of mental states including actual desire, ambivalence, acquiescence and submission, or be constituted by a variety of actions including physical initiation, verbal agreement, or by a lack of action ie a failure to say 'no' or resist. In addition, the extent to which different forms of coercion, deception and lack of mental competence can invalidate consent are hotly contested. ${ }^{14}$ I do not, however, propose to develop a clearer definition of consent. By contrast, I submit that consent is not an appropriate standard by which to distinguish sex from sexual violation.

\section{Consent is inadequate to distinguish sex from sexual violation}

Consent is not an appropriate or effective way to distinguish legitimate sexual activity from sexual violation, for four key reasons. First, consent is enmeshed with a particularly individualistic notion of the Kantian liberal subject and as such is inapt to respond to the bodily, affective and relational dimensions of sexual encounters. Second, consent models support a construction of sexual encounters as inherently asymmetric and unequal. Third, the variable and amorphous nature of sexual activity is poorly-suited to a consent framework. Fourth, consent obscures much of the relevant context within which agreements to engage in sexual activity are made.

\footnotetext{
${ }^{8}$ Ministry of Justice, Home Office and Office for National Statistics 'An Overview of Sexual Offending in England and Wales' (2013).

${ }^{9}$ Liz Kelly, Jo Lovett and Linda Regan, ‘A Gap or a Chasm? Attrition in reported Rape Cases' (Home Office Research Study 293, Home Office Research, Development and Statistics Directorate, 2005).

${ }^{10}$ But see for example Catharine MacKinnon, Towards a Feminist Theory of the State (Harvard University Press 1989) and Victor Tadros, 'Rape Without Consent' (2006) 26 Oxford Journal of Legal Studies 515 for problematisation of the concept of consent itself.

${ }^{11}$ Sexual Offences Act 2003 s74.

${ }^{12}$ See for example Sally Weale, 'Sex Education Should be Mandatory in All Schools, MPs Demand' The Guardian (London 17 February 2015) < http://www.theguardian.com/education/2015/feb/17/sex-education-mandatory-all-schools-mpsdemand> accessed 6 October 2015; University of Sussex Students' Union, 'I Heart Consent Campaign' University of Sussex Students' Union http://www.sussexstudent.com/campaigns/i-heart-consent/ accessed 6 October 2015.

${ }^{13}$ For an overview of this debate see Cowan (n 5).

${ }^{14}$ See discussion in Alan Wertheimer, Consent to Sexual Relations (CUP 2003).
} 


\section{Consent represents a liberal understanding of subjecthood}

The consenting subject is arguably the epitome of the rational liberal subject. ${ }^{15}$ Consent is effectively the granting of certain rights over oneself to another; it plays a central role in liberal discourses of the self as a mechanism by which autonomy is exercised. In the specific context of sexual offences, it functions as the gatekeeper of bodily autonomy, a power to control or limit access to one's body. This framework invokes a Cartesian dualism in which the mind is viewed as the locus of the self, while the body is merely property owned by the self or the vessel in which the self is housed. ${ }^{16}$ Autonomy is then constructed as a cognitive process of reflection and rational choice. As such it obscures the central role that sensation, emotion, bodily realities and relationships with others play in guiding human decision-making, particularly in the area of sexuality. ${ }^{17}$ This has several negative results.

First, the abstract disembodied form of autonomy with which consent is associated leads to a misunderstanding of the wrong of sexual violation. When framed as non-consensual sex, the wrong of rape tends to be understood as a violation of the will, in contradistinction to the body. The removal of choice is certainly one of the wrongs of rape, but it does not fully capture the wrong of this and related offences. Rape is an experience in which bodily contact and physical sensation in combination with the cultural and personal meanings of that contact creates a profound and unique sense of violation. Sexual offence laws that promote a disembodied conception of autonomy are therefore seriously misguided in that by characterising rape and sexual assault as wrongs against the mind, they obscure both the wrong against the body and the extent to which mind and body converge. ${ }^{18}$ This misunderstanding of the wrong of rape can also lead to an underestimation of the harms of rape, particularly in cases where physical violence and injury are relatively minimal. ${ }^{19}$

Second, as a threshold requirement for intimate physical contact, consent emphasizes the policing of bodily boundaries. As such, consent models are associated with a competitive conception of autonomy as isolation or exclusion, through which individuals are encouraged to jealously guard their own interests against those of others rather than taking an interest in each other's desires. ${ }^{20}$ Within this framework potential sexual partners are logically understood as threats (who may violate one's bodily boundaries if one's nonconsent is not enforced), or obstacles (whose consent must be obtained in order to proceed with one's own desires) rather than collaborators in the creation of a mutually satisfying experience.

\footnotetext{
${ }^{15}$ Munro, 'Constructing Consent' (n 5).

${ }^{16}$ Nicola Lacey, 'Unspeakable Subjects: Impossible Rights: Sexuality, Integrity and Criminal Law' (1998) 11 Canadian Journal of Law and Jurisprudence 47; Cowan (n 5).

${ }^{17}$ See Tanya Palmer, Renegotiating Sex and Sexual Violation in the Criminal Law (Hart, forthcoming) for a fuller discussion.

${ }^{18}$ Cowan (n 5); see also Ann Cahill, Rethinking Rape (Cornell University Press 2001) 197.

${ }^{19}$ See for example Donald Dripps, 'Beyond Rape: An Essay on the Difference Between the Presence of Force and the Absence of Consent' (1992) 92 Columbia Law Review 1780.

${ }^{20}$ Jennifer Nedelsky, 'Reconceiving Autonomy: Sources, Thoughts and Possibilities' (1989) 1 Yale Journal of Law and Feminism 7, 12.
} 
Third, the twin emphasis in the liberal autonomy-consent framework on rationality and boundedness (both psychic and physical) sets a threshold for subjecthood which facilitates the exclusion of some categories of people from its remit. Those who supposedly lack stable physical boundaries - eg gay men, all women, and persons with disabilities ${ }^{21}$ - cannot have their boundaries protected, while those deemed to lack a rational will - eg children and individuals with learning difficulties - cannot have their will respected. The sex life of these individuals cannot be easily accommodated within a consent framework and can thus be subject to a separate ethical and legal regime with a different set of rules. An illustration of this can be seen in the proliferation of specific offences against mentally disordered victims under the Sexual Offences Act 2003. ${ }^{22}$ The ostensible neutrality of consent, and liberal subjectivity in general, thus masks its uneven operation in practice.

\section{Consent implies an asymmetric interaction}

Consent is inherently asymmetric. ${ }^{23}$ Framing an interaction as consensual suggests that one party makes a suggestion or request, to which another party can either consent or object. ${ }^{24}$ Consent is therefore a minimal, reactive form of participation. In the specific context of sexual activity, a consent framework implies that sex always involves one (active) person doing something to another (passive) person. ${ }^{25}$ Thus two parties to an encounter are not equally situated. A party who does not want to engage in sex is always at a disadvantage because the consequences of not persuading the other to respect one's interests are far more serious. ${ }^{26}$ Moreover, the differentiated positions of 'initiator' and 'responder' which a consent framework implies are not equally available to all. The distribution of these roles is shaped by strong cultural associations between masculinity, penetration, and sexual assertiveness, even aggression, and between femininity, passivity, and openness or violability. ${ }^{27}$

The uneven burden on the parties is compounded in the context of a criminal investigation and trial. Assuming it is proven that relevant sexual activity between the parties took place, a conviction for rape or sexual assault hinges on two key questions: Did the complainant consent? Did the defendant reasonably believe the complainant was consenting? Both invite an inquiry into the complainant's bodily comportment: did they say or do anything which could be reasonably interpreted as consent? Thus it is the complainant, rather than the defendant, whose actions are investigated. This tendency to 'put the victim on trial' ${ }^{28}$ can be extremely traumatising, and has been likened to a 'second rape'. ${ }^{29}$

\footnotetext{
${ }^{21}$ Lacey (n 16), 115.

${ }^{22}$ Sexual Offences Act 2003, ss30-44; for discussion of these offences and their relationship to consent see Tanya Palmer, 'State Control of Consensual Sexual Behaviour Through the Sexual Offences Act 2003'in Alan Reed, Chris Ashford and Nicola Wake (eds) Consent and Control: Legal Perspectives on State Power (Cambridge Scholars Publishing, forthcoming). ${ }^{23}$ MacKinnon (n 10); Victor Tadros 'No Consent: A Historical Critique of the Actus Reus of Rape' (1999) 3 Edinburgh Law Review 317.

${ }^{24}$ Robert Veatch, 'Abandoning Informed Consent' (1995) 25 Hastings Center Report 5, 5.

${ }^{25}$ Ngaire Naffine, 'Possession: Erotic Love in the Law of Rape' (1994) 57 The Modern Law Review 10.

${ }^{26}$ MacKinnon (n 10), 174.

${ }^{27}$ Nicola Gavey, Just Sex? The Cultural Scaffolding of Rape (Routledge 2005).

${ }^{28}$ Tadros (n 10), 517.

${ }^{29}$ Lee Madigan and Nancy Gamble, The Second Rape: Society's Continued Betrayal of the Victim (Lexington Books 1991).
} 
Distinguishing sex and sexual violation on the basis of consent envisages a question and answer model, whereby one person sets the terms of the interaction and the other can only accept or reject them; it 'does not envision a situation the woman controls being placed in, or choices she frames. ${ }^{30}$ The restrictiveness of this way of thinking is illustrated by the well-used feminist slogan 'no means no', and the more recent variant, 'yes means yes'. Both phrases emphasise a woman's right have her sexual choices respected and challenge a host of lingering myths about female sexuality in a snappy and memorable form. Nevertheless, in centering the right to give or withhold consent, these slogans still position women as answering a question; they do not consider a woman doing the asking. Nor do they make room for the more radical possibility of reciprocity or co-production of sexual experience. As such, they demonstrate the limits of the binary structure of sexual participation presupposed by the consent model. In reality, sexual encounters often develop organically and mutually, without the parties taking on fixed active or passive roles. ${ }^{31}$ Thus, while consent is clearly absent from the worst sexual encounters it will also be absent in the most positive sexual encounters jointly instigated by mutually active partners, because both partners are in a state beyond consent, a state of active involvement and participation rather than reaction or submission. ${ }^{32}$

\section{Consent presupposes an act with clear, fixed parameters}

Consent works well for activities that are very specific in form, and/or where any variability is controlled by one party. So, for example, I can consent to a standing order arrangement whereby my bank transfers a fixed amount of money from my account to my landlord each month to cover my rent. The parameters of this arrangement are established in advance and, provided I am informed of and capable of understanding the terms, it makes sense to say that I consent to them. If I want the arrangement to stop, I can withdraw my consent. Consider another scenario in which I lend my car to a friend. Here again, there will be some pre-defined parameters. Some of these will be explicitly agreed, such as the dates and times during which she will borrow the car. Others may be implicit, for example it will likely go without saying that I do not consent to the vehicle being used for criminal activity. There will nevertheless be some uncertainty in this scenario. I may not know which specific roads my friend will drive on or the exact distance she will cover. To the extent of this uncertainty I am putting myself - or rather my car - in her hands. By consenting I grant her permission to make choices within the agreed parameters. Does consent to sex operate in the same way?

One view of sex, which David Archard has termed the 'climactic model', ${ }^{33}$ holds that 'full sex' consists of penetrative intercourse and (penile) ejaculation, and relegates any other sexual activity to the category of foreplay. On this account, consent to sex operates much like consent to a friend borrowing my car. The key parameters have been specified in advance, and by giving consent one party hands control to the other to do whatever they choose within those parameters. In the car-borrowing scenario the finer details of where, how far and how fast my friend drives the car are all part of one overarching act of borrowing the car, which has been

\footnotetext{
${ }^{30}$ MacKinnon (n 10), 174; for a similar argument see Wendy Brown, States of Injury (Princeton University Press 1995).

${ }^{31}$ Cowan (n 5).

${ }^{32}$ David Archard, Sexual Consent (Westview Press 1998).

${ }^{33}$ For a critique of the climactic model see Archard (ibid.), 22-24.
} 
consented to. If sexual consent operates in the same way, any other sexual touching occurring around the same time as the penetration is counted as part and parcel of one seamless act of sexual intercourse. Archard rightly condemns this model, on the basis that it falsely implies that non-penetrative sexual activity cannot be enjoyed for its own sake and because it underpins the claim that consent to any form of sexual intimacy is consent to penetrative intercourse. ${ }^{34}$

Seemingly at the other end of the scale are models such as the Antioch Sexual Offense Policy of the 1990s, which required explicit verbal consent to every 'level' of sexual activity. ${ }^{35}$ Under this policy, sexual consent operates more like my banking example. Consent is granted explicitly and for a very specific action, which must cease if consent is revoked. The policy was widely mocked and dismissed as unromantic, unrealistic, and requiring far too much of participants in sexual activity. ${ }^{36}$ However, critiques of the policy tend to focus on the requirement of verbal consent, and in doing so mask a deeper flaw. The policy shares the same fundamental problem as the climactic model: it imagines that sex can be broken down into discrete acts. The Antioch policy divides sexual activity into much smaller units, but the underlying approach is the same. Both frameworks construct sex as constituted by individual acts which are fairly definite in form and uniform in character, such that autonomous participation in those acts can be exhausted by the giving or withholding of consent.

In reality, sexual activity is nebulous, variable and mutually produced. As a result, it is ill-suited to a consent framework. Breaking sex down into distinct acts, as per Antioch, does little to address the fact that parties to a sexual encounter need to be able to express something more than mere willingness (or lack of willingness) to participate. They also need to be able to negotiate the quality of that encounter, to express concepts such as 'faster', 'harder', 'that hurts', 'touch me here'. This kind of communication appears peripheral under a consent framework, yet it is central to real world sexual communication. ${ }^{37}$

\section{A consent framework decontextualizes sexual encounters}

A focus on consent can obscure relevant circumstances within which the sexual activity takes place and the reasons why an individual has ostensibly 'consented' ${ }^{38}$ Although a considerable body of literature has explored the way conditions such as coercion, deception and lack of capacity may invalidate an ostensible consent, this debate has operated within fairly strict parameters. The primary focus has been direct interpersonal coercion, deception or inducement at or immediately prior to sexual activity, and individualised medicalised diagnoses that would disrupt a person's capacity to consent. This limited focus finds expression in the conclusive

\footnotetext{
${ }^{34}$ ibid.

${ }^{35}$ Antioch College, 'The Antioch College Sexual Offense Policy,' in Leslie Francis (ed), Date Rape: Feminism Philosophy, and the Law (The Pennsylvania University Press 1996).

${ }^{36}$ For discussion see Matthew Silliman, 'The Antioch Policy, a Community Experiment n Communicative Sexuality', in Francis (ibid.).

${ }^{37}$ Melanie Beres, 'Rethinking the Concept of Consent for Anti-Sexual Violence Activism and Education' (2014) 24

Feminism and Psychology 373.

${ }^{38}$ MacKinnon (n 10), 177; Tadros, 'No Consent' (n 23); Tadros, 'Rape Without Consent' (n 10), 530; Cowan, (n 5).
} 
and evidential presumptions regarding consent and in the specific offences against mentally disordered adults contained within the Sexual Offences Act 2003. ${ }^{39}$

At the same time, feminist and other critical scholarship which highlights the extent to which supposedly consensual choices are shaped by pervasive social and structural forces is often reductively presented as a claim that women's consent is meaningless under patriarchy. ${ }^{40}$ Between these two poles of totalizing patriarchal dominance and almost unfettered free choice, lies the reality of sexual agency. Thus the relevant context for evaluating the validity of consent extends beyond the immediate surrounding conditions in the moment that a decision is taken. It also includes the specific interpersonal dynamic of the parties and the backdrop of the various social structures, chiefly gender, against which they operate. ${ }^{41}$

The need to contextualize sexual consent in this way is particularly significant when considering its operation within abusive intimate relationships. In relationships characterized by 'coercive control', men entrap their female partners through a complex web of techniques including violence, isolation, intimidation and control of material resources. ${ }^{42}$ This constraint at the individual level is further supported by structural constraints on women's autonomy, particularly the default consignment of women to the domestic sphere. ${ }^{43}$ In a relationship of this nature, a woman's liberty is so constrained by her partner that her opportunity to make meaningful choices about many aspects of her life, particularly as they relate to her relationship with her partner, is reduced almost to nothing. However, a consent-based inquiry which extends only as far as the moments immediately preceding sexual activity may obscure more diffuse, unspoken threats of violence and deprivation and find that there was ample opportunity for the victim to refuse sexual activity or simply leave. Only an inquiry into the broader context of the relationship would reveal that there is nothing simple about leaving. ${ }^{44}$

A high proportion of rape and sexual assault is committed by current or former partners of the victim, and yet this subset of offending has proved persistently difficult to bring within the ambit of the criminal law. Abusive relationships are thus a particularly salient example of the dangers of abstraction which accompany frameworks of sexual offending based on consent. They are however only an illustration of a general need to evaluate the legitimacy of sexual encounters in their interpersonal, social, structural and temporal contexts.

\section{Summary: Consent is not an appropriate mechanism for distinguishing sex from sexual violation}

\footnotetext{
${ }^{39}$ Sexual Offences Act 2003 ss 75-76 and 30-44 respectively.

${ }^{40}$ See eg Archard, (n 32); for an overview of the literature see Munro, 'Constructing Consent' (n 5).

${ }^{41}$ Gavey, (n 27); Jennifer Nedelsky, Law's Relations: A Relational Theory of Self, Autonomy and Law (OUP 2012); Palmer, Renegotiating Sex and Sexual Violation (n 17).

${ }^{42}$ Evan Stark, Coercive Control: How Men Entrap Women in Personal Life (OUP 2007), especially Ch 7.

${ }^{43}$ ibid, 211; thus, Stark's theory cannot be straightforwardly mapped onto abusive relationships which do not feature a male abuser and female victim, ibid, 391-397.

${ }^{44}$ ibid, Ch 4; see also Sandra Horley, Power and Control: Why Charming Men Can Make Dangerous Lovers (Vermillion 2000), 90-102.
} 
Despite its broad appeal, consent is not fit for purpose when it comes to the complex task of distinguishing sex from sexual violation. As I have detailed above, consent calls to mind a rather mechanical exchange between parties abstracted from their social context and interpersonal history. One proposes a sexual act, the other rationally considers it, and either accepts or rejects it. If the proposal is accepted, the initiating party performs the act. This image is a world away from the ongoing process of reciprocal interaction that is the substance of most (if not all) non-violating sexual encounters. As a result, the concept of consent has significant limitations as a tool for evaluating the legitimacy of sexual encounters. It is ill-equipped to make sense of sexual activity involving parties who are incapable of either giving or withholding consent, and it fails to make sense of the many forms sexual coercion can take beyond specific immediate threats.

Despite its inadequacies, consent remains preferable to previously dominant ethical frameworks that restrictively defined sexual violation as sexual activity imposed via physical force, and/or adopted a conservative sexual morality under which non-marital and nonheterosexual sex are viewed as illegitimate. With this in mind, consent may be best thought of as a 'transition concept... that appears on the scene as an apparently progressive innovation, but after a period of experience turns out to be only useful as a transition to a more thoroughly revisionary conceptual framework. ${ }^{45}$ In what follows, I explore the possibilities for a more radical conceptual framework.

\section{Negotiation and communicative sexuality}

Lois Pineau's path-breaking text 'Date Rape: A Feminist Analysis', published in 1989, introduced the concept of 'communicative sexuality' as a means of refocusing attention from snap-shot moments of consent or resistance on the part of a woman to 'a reading of whether she agreed throughout the encounter'. ${ }^{46}$ Pineau's central premise is that non-communicative sex, ie where the woman does not instruct her partner how and where to touch her and he does not ask, will most likely not be enjoyable for her, and it is therefore unreasonable for either the man having sex with her or a jury evaluating the scenario after the fact to believe that she consents. ${ }^{47}$ This does not rule out consent in the absence of ongoing communication between the parties to a sexual encounter, but sets up a presumption against it, such that the man would have to be certain (and able to explain why he was certain) that she was, in fact, consenting and had a reason to do so other than reluctant acquiescence to the man's 'high pressure' tactics. ${ }^{48}$ Subsequently, an emerging body of literature, both academic and non-academic, has explored similar themes to Pineau, whilst not necessarily building on her ideas explicitly. ${ }^{49} \mathrm{~A}$ pertinent example is Michelle Anderson's proposed 'negotiation model', under which explicit

\footnotetext{
45 Veatch (n 5), 5.

${ }^{46}$ Lois Pineau, 'Date Rape: A Feminist Analysis' (1989) 8 Law and Philosophy 217, 231; see also Francis (n 35).

${ }^{47}$ In this passage I specifically refer to male perpetrators and female victims in keeping with Pineau's formulation.

${ }^{48}$ Ibid, 230.

${ }^{49}$ See for example Cowan, (n 5); Thomas Macaulay Millar, 'Toward a Performance Model of Sex' in Jaclyn Friedman and Jessica Valenti (eds) Yes Means Yes: Visions of Female Sexual Power and a World Without Rape (Seal Press 2008); Rachel Kramer Bussel, 'Beyond Yes or No: Consent as Sexual Process' in Friedman and Valenti (eds), ibid.
} 
verbal communication, or rather its absence, would be central to the definition of rape in criminal law. ${ }^{50}$

A framework for sexual offending based around communication or negotiation holds considerable potential for decentering consent and related notions of sexual encounters as asymmetric proposals of discrete, well-defined acts, and in its place emphasizing the relationality, mutuality and fluidity of sexual encounters. By emphasizing reciprocal dialogue, a negotiation standard encourages individuals both to articulate and engage with their own desires and to pay attention to those of their partner. Moreover, communicative sexuality more closely maps the way that sexual activity is agreed in practice than consent does - it is often through ongoing active participation, directing and shaping of the activity that individuals express their willingness to engage in a sexual act, as opposed to a one-off moment of agreement or refusal. ${ }^{51}$ Understanding non-violating sexual encounters as produced through a process of negotiation and ongoing communication also provides greater scope than a consent framework for considering the context in which agreement about a sexual practice was reached, though realizing this potential creates some tensions, explored below.

An additional advantage of communicative sexuality is that it places the spotlight on the defendant's, rather than the complainant's, conduct. In Anderson's words, 'Instead of asking, "What did she let him do?" the Negotiation Model asks, "Did the person who initiated sexual penetration negotiate with his or her partner and thereby come to an agreement that sexual penetration should occur?" 52 Pineau similarly advocates asking the defendant whether he thought the complainant was enjoying the sexual activity. If not, why was it reasonable for him to think she agreed to it? If yes, how did he know? Did he ask her what she liked? Did they discuss contraception? What desires did she communicate and how $?^{53}$ Thus in a rape trial, the central question would focus on the behaviour of the accused. A negotiation standard would therefore address several of the problems with consent identified above. Nevertheless, attempts to operationalize communicative sexuality within the criminal law reveal some weaknesses.

Reformulating sexual offences law around negotiation requires decisions to be made about what exactly will satisfy the negotiation condition and which acts need to be negotiated. For Anderson, verbal negotiation is essential so that silence cannot be taken as consent to sex. Her concern is that existing consent models place the onus on the victim to verbally or physically resist their attacker, an unfair requirement given that victims of rape are often paralysed by fear. ${ }^{54}$ In Anderson's view, affirmative consent requirements cannot solve this problem, because consent to other forms of sexual intimacy, eg passionate kissing or petting, can be taken as consent to intercourse, so that once a person willingly engages in some sexual activity, they acquire the responsibility to clearly communicate any objection to sexual penetration. However, conscious of the criticisms of the Antioch Policy which required verbal

\footnotetext{
${ }^{50}$ Michelle Anderson, 'Negotiating Sex' (2005) 78 Southern California Law Review 1401.

${ }^{51}$ Pineau (n 46); Cowan, (n 5); Beres (n 37).

52 Anderson (n 50), 1423.

${ }^{53}$ Pineau, (n 46), 240-241.

${ }^{54}$ Anderson, (n 50), 1405.
} 
consent to every level of sexual activity (above), Anderson stresses that her negotiation requirement only applies to penetrative sex, and creates an exemption for parties who have 'established a context in which they could reliably read one another's nonverbal behavior to indicate free and autonomous agreement. ${ }^{55}$ Applying these parameters has the effect of privileging penetrative sex and long term relationships, despite the prevalence of sexual violation within relationships. A more fundamental problem, however, is that the requirement of explicit verbal negotiation shifts the focus back to episodic moments of agreement or refusal, with all the problems this entails for existing models of consent.

By contrast, Pineau's proposal emphasises the need for continuing alertness by each party to the others' desires, and calls for evidence of ongoing communication to establish the legitimacy of a sexual encounter, as opposed to evidence of a specific moment of agreement. Unlike Anderson, Pineau does not specify that communication must be verbal, and this is what allows for a more fluid understanding of negotiation. Pineau does not share Anderson's concerns about participation in one act of sexual intimacy being taken as consent for another because, as she demonstrates, there is scope for non-verbal forms of communication about sex that are reasonably clear, such as guiding another party's hand to the place one wishes to be touched. ${ }^{56}$ Nevertheless, it is tolerably clear that in some instances individuals will need to use explicit words to negotiate their participation in a sexual encounter without misunderstanding, but the need for this is idiosyncratic and cannot be straightforwardly mapped on to the nature of the sex act or the length of the relationship, as Anderson suggests.

Nevertheless, Pineau's formulation of communicative sexuality also has some problems. Like Anderson, she does not fully exploit the potential of a negotiation framework to widen the contextual lens through which consent is evaluated. She does extend the focus of the enquiry to cover the duration of the sexual activity, whereas consent models, and even Anderson's negotiation model, are interested primarily in the moments immediately preceding a specified sexual act (unless there is clear evidence of the complainant later revoking consent). However, Pineau states that any prior behaviour or reputation of the parties should be excluded from the inquiry, and that, "All that matters is the quality of communication with regard to the sex itself ${ }^{57}$ Fixing the parameters as such is in order to exclude irrelevant evidence of the complainant's sexual history from the enquiry. However, in doing so Pineau also excludes evidence of previous abuse by the defendant that may be relevant to understanding the quality of the complainant's communication at the relevant moment.

In addition, the essence of Pineau's proposal is that, 'Where communicative sex does not occur, this establishes a presumption that there was no consent. ${ }^{, 58}$ This reverses the burden of proof, such that the defendant is required to prove that the complainant did in fact consent despite the likely unsatisfying nature of the sex. ${ }^{59}$ I share Pineau's concerns about the tendency

\footnotetext{
55 ibid, 1425; for a similar approach see Tadros, 'Rape Without Consent' (n 10), 529 and 541; Archard, (n 32), 25-27.

${ }^{56}$ See further Pineau, 'A Response to My Critics' in Francis (n 35), 96-98.

${ }^{57}$ Pineau, (n 46), 242.

58 ibid, 242.

${ }^{59}$ ibid, 233.
} 
for rape victims to be 'put on trial' themselves, as detailed above. However, the burden of proof exists to protect defendants against the illegitimate infringements of their liberty by the state, and should not be abandoned lightly. Moreover, in requiring the defendant to prove that the complainant consented (provided the presumption has been triggered), Pineau's formula retains a focus on the complainant's behavior - did she or did she not consent? Thus the presumption approach involves a significant erosion of the presumption of innocence, with minimal gain for complainants. Communicative sexuality and negotiation offer a promising starting point for rethinking sex and sexual violation, but the weaknesses identified suggested further revisions are necessary, as I explore in the following section.

\section{From negotiation to 'freedom to negotiate'}

Negotiation and communicative sexuality provide a useful starting point for rethinking sexual offences law so as to pay attention to the interactive and processual nature of sexual encounters. Nevertheless, these ideas need further development to provide a viable alternative to consent. In this final section I consider how the concept of negotiation might be developed in order to overcome its weaknesses. This development is informed by data from an original qualitative study into understandings of sex and sexual violation. ${ }^{60}$

Who is responsible for negotiating sexual activity?

Communicative sexuality is distinctive because, in theory, it treats ongoing reciprocal interaction as the paradigm form of legitimate sexual activity, rather than an asymmetric model of initiation and acceptance. ${ }^{61}$ Pineau specifically seeks to challenge discourses of seduction and submission which normalize male sexual aggression and female reluctance. ${ }^{62}$ Similarly, Anderson is concerned that 'girls' are 'too often trained to acquiesce to male desire' rather than being treated as 'human being[s] whose desires and boundaries matter.' ${ }^{63}$ Both authors contest the idea that a dynamic of male initiation and female passivity, whereby a man may carry out his sexual desires unless and until his female partner resists, should be acceptable. In order to delegitimise this kind of interaction, they propose additional obligations on the initiator to verbally ask first and/or to maintain communication throughout the encounter to ensure that the other party is consenting. However, models which attach additional requirements to the initiation of sexual activity arguably reify an active-passive construction of sexual interaction, and are poorly equipped to deal with sexual encounters that do not fit this mould.

This can be illustrated using a sexual experience reported by Rosa, a lay volunteer I interviewed for a study of understandings of sex and sexual violation. ${ }^{64}$ Rosa described an experience within an 'unhealthy' relationship, which she initially described as 'not quite rape':

\footnotetext{
${ }^{60}$ For a detailed discussion of the methodology and findings of this study, see Palmer Renegotiating Sex and Sexual Violation (n 17).

${ }^{61}$ Cowan, (n 5).

${ }^{62}$ Pineau, (n 46).

${ }^{63}$ Anderson, (n 50), 1438.

${ }^{64}$ For further analysis see Palmer, Renegotiating Sex and Sexual Violation, (n 17).
} 
Rosa: There was one particular afternoon, he came back in a foul mood, and I knew he was gonna hit me, and I didn't wanna get hit, um, so I just jumped his bones instead. And it wasn't making love, it wasn't sex. It was a really hard brutal fuck. I'm sorry for being blunt here, I was just bouncing up and down on his lap. And it was, it was almost vicious, I didn't hit him, he didn't hit me, but I, I, I knew he had to let that anger out, and I didn't want to get hit. Um, so I just, I hate saying this, rode him for all I was worth. Just in a, it was almost like I was the one going, 'I'm gonna fuck you!' I thought, although physically he was inside me, as far as the emotional power struggle went, and the control, I was fucking him. And it stopped him hitting me. Um, and it was one of the most powerful and intense experiences I've ever had, I would never like to repeat that ever again. The sex was amazing! But the fact that I had to instigate it in that way, to stop him from hitting me, absolutely appalling and dreadful.

Tanya: And, I mean you started off as describing it as 'not quite rape' but as 'having sex against your will'

Rosa: Yeah, 'cause if I, if I didn't do that, if I didn't - excuse my French - if I didn't fuck him the way I did, he'd have ended up hitting me and hurting me.

Tanya: And in terms of -

Rosa: And so I just had this really rough sex with him to avoid him hitting me. And as far as I'm concerned, yeah it was powerful, it was mental, but it was rape! I didn't wanna have sex with him, but more than I didn't wanna have sex with him I didn't want him to fucking hit me again!

Both Anderson and Pineau's constructions of communicative sexuality have limited utility in a situation of this nature.

If this scenario is analysed using Pineau's model, the central issues are, was it reasonable for Rosa's partner to think she enjoyed the sex? And if not, was it reasonable for him to nevertheless think she was consenting? Pineau assumes that it is not reasonable to think a woman is enjoying sexual activity in the absence of communication with her partner. However, in this scenario, Rosa's own admission that 'the sex was amazing!' (despite also being 'appalling', 'dreadful' and unwanted) and the fact that she 'jumped his bones', would make it very difficult to argue that it was unreasonable for her partner to think she enjoyed the sex. Even if the lack of communication was taken as sufficient evidence for a presumption of non-consent, it would also be fairly easy to rebut this presumption given that she initiated the sexual activity. By insisting that 'all that matters is the quality of communication with regard to the sex itself', ${ }^{65}$ Pineau excludes evidence of the wider history of violence and abuse within which that sexual act took place, and its effect on Rosa's ability to make a free choice. While Pineau's model would struggle to recognize Rosa's experience of violation, under Anderson's model she would potentially be constructed as the violator.

Anderson's negotiation model specifically requires a person initiating sexual penetration to first verbally negotiate and gain explicit verbal agreement. Assuming that this includes a person initiating the sexual penetration of their own body (Anderson is unclear on this point), a person in Rosa's position who initiates penetrative sexual activity without negotiating first, would have committed an offence of rape. Arguably, Rosa could be saved by Anderson's exception whereby explicit verbal negotiation is not required if the parties have established a context within which they can reliably read each other's non-verbal signals. It

${ }^{65}$ Pineau, (n 46), 242. 
does seem to be the case that Rosa could read her partner's body language, however what she 'read' in it was not 'I am agreeing to have sex with you' but rather 'I am going to hit you if you don't find some way to diffuse the situation.' This hardly seems to be what Anderson envisaged with this exception.

Both models struggle to make sense of the encounter between Rosa and her partner because they assume an initiator-responder model of sexual interaction. The strategy of placing additional burdens on the initiator of sexual activity has the undesirable consequence of reinforcing the idea that one person takes the lead in sexual encounters and as a result falls back into many of the same traps as existing consent models, by constructing sex as an asymmetric interaction characterized (at least in Anderson's case) by neatly delineated acts which can be agreed to or refused. In addition, models of communicative sexuality which focus narrowly on the form and content of the negotiation between the parties repeat consent's mistake of abstracting sexual encounters from their wider context. The wrongful aspect of the scenario described by Rosa is not the lack of communication on the part of either party, but rather the surrounding circumstances in which the sexual activity is initiated - something that is obscured by a focus on the negotiation between the parties immediately prior to and throughout the duration of the sexual activity. The question of whether this particular incident should be classed as criminal sexual violation would require a fuller enquiry into the behaviour of Rosa's partner both at the time of the sexual activity and earlier in the relationship, and the extent to which this constrained Rosa's choices at the given time. There is no room to ask these questions under a model that only examines negotiation at the time of the sex.

\section{Negotiation and the 'room to say no'}

Verbal negotiation is central to Anderson's distinction between sex and sexual violation because her aim is to counteract existing consent models under which silence is treated as consent. Anderson rightly draws attention to the problems inherent in expecting a party who is unwilling to engage in sexual activity to bear the burden of expressing dissent. However, requiring individuals initiating sexual activity to first verbally discuss it with their intended partner would not necessarily make it any easier to say 'no' rather than 'yes' to the proposed sexual activity. Both the tone of the negotiation and the context in which it takes place can render a verbal proposal oppressive.

The tone in which desires are communicated can have a significant impact on how they are received. A verbal request can be spoken in such a way as to make it clear that there is only one acceptable answer, while a different tone of voice would transform it into a sincere question. Similarly, while physical contact with another person can be forceful, can restrict freedom and can prevent resistance, physical touch can also be initiated tentatively, in such a way as to invite another party to respond freely. The tone of communication (inviting rather than insisting) is therefore more important than the form it takes (verbal rather than physical) in terms of preventing situations where one party unwillingly submits to sexual activity through lack of choice. The context in which sexual negotiation takes place is similarly important for ensuring it is genuinely free negotiation. 
In a focus group with domestic violence support workers, Eve described the way that cultural expectations might restrict a person's options when negotiating sexual encounters:

[I]n the $80 \mathrm{~s} . .$. there was no room to say no really to sex. And I'm pretty certain it's the same now. There was no way of justifying saying no. 'Cause there was the pill and then there was the coil, condoms, blah blah blah, the whole thing about society, our society, was that we were sexually liberated. Which meant actually we had to put out. ${ }^{66}$

Eve's reference to the 'room to say no' suggests that in the context she describes the problem is not so much a lack of verbal communication, but the location of that communication within a cultural environment that restricts women's freedom to express their desires openly. Within such a context the initiation of verbal communication regarding a proposed sex act could appear less like an attempt at open dialogue and more like a demand. Eve here is focused on broad socio-cultural contexts of sexual interaction. These intersect with the narrower context of specific interpersonal relationships which can also restrict an individual's freedom to say 'no' where sexual communication is set against a backdrop of past abuse. I therefore advocate a shift in emphasis for communicative sexuality, placing the focus on the surrounding circumstances within which negotiation occurs, rather than on the content of the negotiation itself.

It would be unfair to claim that communicative sexuality models take no account of context whatsoever. Anderson explicitly states that, 'Force, coercion, or misrepresentations by the actor would be evidence of a failure to negotiate. ${ }^{, 67}$ Anderson's model could therefore be understood as consisting of two requirements: A requirement that the parties reach an explicit verbal agreement to engage in the sexual behaviour, and a requirement that both parties are free to negotiate the terms of that agreement. Without the freedom to negotiate, explicit verbal agreement is meaningless. A person may say 'yes' to an offer of sexual penetration, but if the other party is holding a gun to their head at the time, the subsequent intercourse will still be an instance of sexual violation. What happens if, instead, we take away the requirement of explicit verbal agreement?

If two or more parties to a sexual encounter all feel able to openly express their desires and their boundaries, but choose not to do so verbally, is it right to say that any of those parties has violated the other(s)? I submit that sexual penetration unaccompanied by verbal negotiation is not, of itself, an appropriate target for criminalization. Instead, the focus of the criminal law should be on sexual activity which is unilaterally imposed on a person who lacks the opportunity, the freedom or the ability to refuse to engage in, or to actively participate in shaping, the sexual encounter. This would cover situations where a person's refusal is ignored, as well as situations when a person is prevented from expressing refusal in the first place. Central to the legitimacy of a given sexual encounter should be the creation and maintenance of a space within which negotiation can freely take place.

\footnotetext{
${ }^{66}$ For further analysis see Palmer, Renegotiating Sex and Sexual Violation, (n 17).

${ }^{67}$ Anderson, (n 50), 1407.
} 


\section{Freedom to negotiate: a possible way forward for law reform?}

Consent is not an effective mechanism with which to distinguish sex from sexual violation. Negotiation and communicative sexuality represent a move in the right direction, but they focus too heavily on the form and content of negotiation and marginalize the context in which it takes place. I propose a standard of 'freedom to negotiate' as an alternative framework for sexual offences law. The core of the proposal is a restructuring of the existing offences of rape and sexual assault under ss1-4 of the Sexual Offences Act 2003. These offences relate to different categories of sexual activity, but share a common actus reus element, that the designated sexual activity takes place without the victim's consent. It is submitted that the requirement of nonconsensual sexual activity should be replaced by an actus reus element of sexual activity performed on a person who lacks the freedom to negotiate their participation in that activity.

It could be argued that this requirement is already incorporated in the definition of consent under section 74 of the 2003 Act, which provides that 'a person consents if he agrees by choice, and has the freedom and capacity to make that choice.' The law already prohibits sexual activity with a person who lacks the freedom to choose. In fact, replacing consent with freedom to negotiate involves a radical reframing of the relevant inquiry. The central questions for identifying criminal sexual violation are no longer about the actions of the complainant did they consent? Or did they do anything which could give rise to a reasonable belief in their consent to sex? These are replaced with questions about the behaviour of the defendant: did they do anything to restrict the complainant's freedom? Did they make the complainant feel like their wishes would not be respected? Did they ignore the complainant's words or body language? Changing the central questions in this way has important practical and symbolic consequences.

In terms of practical consequences, reframing rape and sexual assault law around a concept of freedom to negotiate would benefit both victims and suspects in the investigation and trial process. A freedom to negotiate model puts the focus where it should be: on interrogating the defendant's behaviour in context, rather than primarily scrutinizing the complainant's behaviour to ascertain whether it gave rise to a reasonable inference of consent. In addition, it provides greater scope for victims to articulate on their own terms the ways in which their freedom to negotiate sex was constrained within the context of the particular relationship and the particular encounter in question, rather than requiring them to categorise their experience as strictly consensual or non-consensual, a framework which may not easily map onto their experiences. Under freedom to negotiate the prosecution would be required to produce evidence demonstrating that the victim's freedom to negotiate their role in the sexual activity was constrained, and showing how the defendant either contributed to or took advantage of this constraint. This would mitigate the tendency to 'put the victim on trial' as the prosecution would not need to prove an absence of consent, which in practice often requires evidence of sufficient resistance by the victim. ${ }^{68}$ At the same time however, the presumption of innocence would be preserved as there would be no implicit or explicit reversal of the burden

${ }^{68}$ Munro, 'From Consent to Coercion', (n 6). 
of proof requiring the defendant to prove that they did communicate sufficiently with the victim, as Pineau advocates. ${ }^{69}$

Symbolically, introduction of a freedom to negotiate model would mark a significant shift in the way sex and sexual violation are conceptualized. The proposed formulation frames sexual encounters as dynamic processes of interaction rather than discrete, easily divisible events. It emphasizes the relational, affective and embodied dimensions of sexuality and provides greater scope to take account of context and the power relations between the parties when evaluating a given sexual encounter. As such it more closely maps the messy reality of sexual encounters than an abstract consent standard. The linguistic break with consent and the unfamiliarity of the new terminology would also provide an opportunity for public discussion and consideration of the parameters of ethical and legal sexual activity. By contrast efforts to reframe consent or re-educate people about its meaning are obstructed by the considerable conceptual baggage which that term carries and the proliferation of existing meanings with which it is associated.

The model which I have outlined here is presented as a starting point for rethinking the distinction between sex and sexual violation in criminal law. There are of course numerous details which remain to be developed and which there is not scope to explore here. Some of these questions are familiar. Like consent, consideration must be given to the kinds of force, coercion or deception that would restrict a person's freedom to negotiate, and the extent to which this freedom must be restricted in order to attract criminal liability. In this area, a freedom to negotiate model would in principle broaden the lens through which coercion can be considered, to look beyond direct and explicit threats immediately prior to the sexual activity. The vexatious issue of the mens rea of rape would remain, but the terrain of the debate would be relocated. Instead of oscillating between reasonable and honest belief in consent, discussion would now focus on whether a defendant must have intentionally, knowingly, recklessly or negligently restricted the victim's freedom to negotiate, or exploited existing restrictions on the victim's freedom. A subjective mens rea standard might be more palatable where it relates to a defendant's awareness of constraint and coercion as opposed to belief in consent. More radically, a freedom to negotiate model would also provide a basis for rethinking the relationship between rape and sexual assault and many of the other offences contained within the Sexual Offences Act 2003. This model foregrounds power disparities between the parties which prevent one individual from negotiating their participation in sexual activity. As such, it calls into question whether separate offences against children ${ }^{70}$ or against mentally disordered adults ${ }^{71}$ address a different form of sexual violation from rape and sexual assault, and whether there is a clear rationale for these additional offences.

\section{Conclusions}

\footnotetext{
${ }^{69}$ Pineau, (n 46), 224.

${ }^{70}$ Sexual Offences Act 2003, ss5-29.

${ }^{71}$ Sexual Offences Act 2003, ss30-44.
} 
Despite its broad appeal, consent is not an appropriate or effective way to distinguish legitimate sexual activity from sexual violation. Consent models invoke the abstract, disembodied, rational subject of liberal discourse and emphasise the policing of bodily boundaries as opposed to the relationality and intersubjectivity of sexual encounters. Consent is therefore useful for conceptualizing asymmetric proposals and agreements to discrete acts, but poorly suited to evaluating dynamic interactions between parties, absent clear fixed parameters, which constitute the bulk of real world sexual encounters. Consent models also have limited capacity for taking account of the contexts within which sexual activity is negotiated. Reframing the distinction between sex and sexual violation around a concept of negotiation or communication addresses many of these problems in theory, by constructing sexual encounters as ongoing processes of reciprocal interaction rather than episodic moments of consent or refusal. However, adopting a narrow focus on communication immediately prior to and during sexual activity reproduces several of consent's flaws. A concept of freedom to negotiate, which is informed by negotiation models as well as by original empirical research, is proposed as the basis for a radical rethinking of sexual offences law. At its core, freedom to negotiate emphasizes the context in which sexual activity takes place, requiring that, at a minimum, all parties to sexual activity should have the space to negotiate both the fact and nature of their participation throughout the duration of that activity. 